\title{
Zinc oxide nanoparticles as selective killers of proliferating cells
}

This article was published in the following Dove Press journal:

International Journal of Nanomedicine

28 May $201 \mathrm{I}$

Number of times this article has been viewed

\author{
Liuba Taccola' \\ Vittoria Raffa ${ }^{2}$ \\ Cristina Riggio ${ }^{2}$ \\ Orazio Vittorio ${ }^{1,2}$ \\ Maria Carla lorio ${ }^{3}$ \\ Renato Vanacore ${ }^{3}$ \\ Andrea Pietrabissa ${ }^{4,5}$ \\ Alfred Cuschieri ${ }^{2}$ \\ 'Department of Oncology, \\ Transplantation and Advanced \\ Technologies in Medicine, University \\ of Pisa, Pisa; ${ }^{2}$ Medical Science \\ Laboratory, Scuola Superiore \\ Sant'Anna, Pisa; ${ }^{3}$ Laboratory of \\ Immunogenetics, Immunohematology, \\ Azienda Ospedaliera Universitaria \\ Pisana, Pisa; ${ }^{4}$ Department of \\ Surgical Science, Reanimation and \\ Transplantation, University of Pavia, \\ Pavia; ${ }^{5}$ Fondazione Policlinico San \\ Matteo, Pavia, Italy
}

Correspondence: Vittoria Raffa Medical Science Laboratory, Scuola Superiore Sant'Anna, P.zza Martiri della Libertà 33 , Pisa 56127, Italy

Tel +390 50995625

Fax +390 50995676

Email v.raffa@sssup.it
Background: It has recently been demonstrated that zinc oxide nanoparticles ( $\mathrm{ZnO}$ NPs) induce death of cancerous cells whilst having no cytotoxic effect on normal cells. However, there are several issues which need to be resolved before translation of zinc oxide nanoparticles into medical use, including lack of suitable biocompatible dispersion protocols and a better understanding being needed of the mechanism of their selective cytotoxic action.

Methods: Nanoparticle dose affecting cell viability was evaluated in a model of proliferating cells both experimentally and mathematically. The key issue of selective toxicity of ZnO NPs toward proliferating cells was addressed by experiments using a biological model of noncancerous cells, ie, mesenchymal stem cells before and after cell differentiation to the osteogenic lineage.

Results: In this paper, we report a biocompatible protocol for preparation of stable aqueous solutions of monodispersed zinc oxide nanoparticles. We found that the threshold of intracellular $\mathrm{ZnO}$ NP concentration required to induce cell death in proliferating cells is $0.4 \pm 0.02 \mathrm{mM}$. Finally, flow cytometry analysis revealed that the threshold dose of zinc oxide nanoparticles was lethal to proliferating pluripotent mesenchymal stem cells but exhibited negligible cytotoxic effects to osteogenically differentiated mesenchymal stem cells.

Conclusion: Results confirm the ZnO NP selective cytotoxic action on rapidly proliferating cells, whether benign or malignant.

Keywords: zinc oxide nanoparticles, dispersion, selective cytotoxicity, mesenchymal stem cells

\section{Introduction}

Nanomaterials have been the subject of increasing research attention in recent years because of their potential biomedical and life science applications. Among the various nanomaterials, zinc oxide nanoparticles offer significant benefits, and are used in several products and systems, including sunscreens, biosensors, food additives, pigments, rubber manufacture, and electronic materials. ${ }^{1}$ In the biomedical field, one of the most important attributes of these nanoparticles is their antibacterial activity, with published reports confirming the efficacy of zinc oxide nanoparticle-based preparations as prophylactic agents against bacterial infections. ${ }^{2,3}$ However, to date, there have been few reports on the cytotoxicity of zinc oxide nanoparticles to mammalian cells, with no clear consensus among scientists on the significance of published results. One study reported that zinc oxide particles have minimal effects on the viability of primary human $\mathrm{T}$ cells at concentrations toxic to both Gram-negative and Gram-positive bacteria. ${ }^{4}$ Other reports suggest that these nanoparticles are nontoxic to cultured human dermal fibroblasts, ${ }^{4}$ but exhibit toxicity towards neuroblastoma cells ${ }^{5}$ and vascular endothelial cells,${ }^{6}$ and induce apoptosis in neural stem cells. ${ }^{7}$ It has also 
been reported that nanoparticle size influences cell viability. Jones et al pointed out that zinc oxide particles of $8 \mathrm{~nm}$ in size were more toxic than larger zinc oxide particles $(50-70 \mathrm{~nm})$ in Staphylococcus aureus. ${ }^{8}$ Recently, Hanley et al observed that there is an inverse relationship between nanoparticle size and cytotoxicity in mammalian cells, as well as nanoparticle size and reactive oxygen species production, ${ }^{9}$ while Deng et al showed that zinc oxide nanoparticles manifested dose-dependent, but no size-dependent, toxic effects on neural stem cells. ${ }^{7}$ In our opinion, many of the reported studies on zinc oxide nanoparticle toxicity have significant limitations for two reasons. Firstly, some reports used zinc oxide nanoparticles with different characteristics (size, shape, and purity) and, secondly, the dispersion protocols used have often been unsuitable for biological use. In largescale production of nanoparticles, the as-prepared material exists as agglomerates, with sizes of up to hundreds of microns. The reason for this is that zinc oxide nanoparticles (like all nanomaterials) have high superficial energy, resulting in decreased interactions with the environment and an intrinsic tendency to clustering in aqueous solutions. However, biological applications involving interactions between nanoparticles and living cells require aqueous dispersion of single nanoparticles. Thus, the first requirement for the biomedical use of zinc oxide nanoparticles is an effective biocompatible protocol for aqueous dispersion. The current reported methods for zinc oxide nanoparticle dispersion with biocompatible additives do not ensure monodispersion of the nanoparticles, ${ }^{4,7,10,11}$ resulting in the presence of clusters and macroscopic agglomerates. These preclude meaningful investigation of their interactions with target cells. For example, Deng et al investigated the toxicity of zinc oxide nanoparticles (size $10 \mathrm{~nm}, 30 \mathrm{~nm}, 60 \mathrm{~nm}$, and $200 \mathrm{~nm}$ ) which were sonicated in phosphate-buffered saline for 30 minutes and then in complete medium, ${ }^{7}$ but the resulting aqueous solution contained significant clusters and nondispersed particles. Similarly, the aqueous solution used by Zhao et al to evaluate the cytotoxicity of these nanoparticles had many zinc oxide aggregates. ${ }^{10}$ Some researchers have suggested surface modification to improve zinc oxide nanoparticle dispersion. ${ }^{1-13}$ Such protocols have usually involved the use of nonbiocompatible reagents which were subsequently removed. Other authors have proposed de novo synthesis of monodispersed zinc oxide nanoparticles. The method consists of hydrolysis of zinc acetate in diethylenic glycol.,14,15 The toxic diethylenic glycol is removed by centrifuging and washing several times in ethanol. Although this method enables production of monodispersed nanoparticle solutions, protocols which avoid the use of toxic materials are preferred for cytotoxicity studies. In essence, all approaches currently available either produce stable nanoparticle solutions which contain nanoparticle clusters or aqueous monodispersions with residual toxic materials in addition to the nanoparticles.

The primary aim of the present study was to develop a protocol for the preparation of biocompatible solutions of individually dispersed zinc oxide nanoparticles. This monodispersion protocol enabled us to proceed with the second part of the investigation which focused on the cytotoxicity of these nanoparticles and mechanisms of cell death. We estimated the threshold dose of zinc oxide nanoparticles which affects the viability of proliferating cells. The study was carried out in a human neuroblastoma cell line which can be easily used in a mathematical model.

Finally, we investigated the potential application of zinc oxide nanoparticles in medicine as a follow-on from the report by Hanley et al that these nanoparticles induce toxicity in a cell-specific and proliferation-dependent manner. This group demonstrated that zinc oxide nanoparticles exhibit a strong preferential ability to kill rapidly dividing cancerous T cells $(28-35 \times)$ but not normal cells. ${ }^{14}$ A recent report confirmed that these nanoparticles exert a cytotoxic effect on human glioma cells, but not on normal human astrocytes. Similarly, zinc oxide nanoparticles induce cell death in breast and prostate cancer cell lines, but have no major cytotoxic effects on normal breast and prostate cells. ${ }^{16}$ The mechanisms of toxicity appear to involve the generation of reactive oxygen species, with cancerous cells producing higher inducible levels than normal cells. In the present study, we investigated the proliferation-dependent cytotoxicity of zinc oxide nanoparticles in a biological model of noncancerous cells.

\section{Materials and methods Preparation of zinc oxide nanoparticles}

Zinc oxide nanoparticles were supplied in highly purified form (99.9\%) from Nanostructured and Amorphous Materials Inc, Houston, TX. The production method essentially involves synthesis of the nanoparticles by solid vapor deposition. ${ }^{16}$ These as-produced nanoparticles range between $90 \mathrm{~mm}$ and $200 \mathrm{~nm}$ in size.

For dispersion of the nanoparticles, we tested the following biological reagents: polyethylene glycol 8 K (P2139 Sigma-Aldrich, St Louis, MO), polyethylene glycol $14 \mathrm{~K}$ (637726 Sigma-Aldrich), poly(ethylenimine) (40872-7 Sigma-Aldrich), polyvinyl alcohol (363170 Sigma-Aldrich), gelatin (48723 Sigma-Aldrich), Pluronic ${ }^{\circledR}$ PF127 (P-2443 
Sigma-Aldrich), sodium dodecyl sulfate (L4390 SigmaAldrich), Arabic gum (51200 Sigma-Aldrich), glycine (04055 Sigma-Aldrich), horse serum (ECS0091D Euroclone), and bovine serum albumin (A9418 Sigma-Aldrich).

Briefly, an aqueous solution of biological reagents containing zinc oxide nanoparticles $100 \mu \mathrm{g} / \mathrm{mL}$ was vortexed for five minutes. The resulting mixture was sonicated [for polyethylene glycol, poly(ethylenimine), polyvinyl alcohol, gelatin, PF127, sodium dodecyl sulfate, Arabic gum, glycine] in a $20 \mathrm{~W}$ sonication bath (AGE Electronica SRL, Italy) or magnetically stirred (for horse serum, bovine serum albumin) overnight. The mixture was then centrifuged at $900 \mathrm{~g}$ for 10 minutes at room temperature to remove any residual nonsuspended nanoparticles and impurities. The concentration of the nanoparticles was measured by spectrophotometric analysis at the wavelength of $380 \mathrm{~nm}^{18}$ after calibration.

\section{Size distribution}

Electron imaging was performed with a scanning electron microscope (FEI XL20) equipped with energy dispersive spectroscopy microanalysis (EDAC model). A drop of the solution (concentration $10 \mu \mathrm{g} / \mathrm{mL}$ ) was transferred onto a silicon substrate and allowed to dry under laminar flux overnight at room temperature. The sample was then washed with ethanol to remove the excess polymer. The size distribution of the dried nanoparticles was monitored using image analysis software "Image J" (http://rsb.info.nih.gov/ij/). The size distribution of the nanoparticles in media was monitored by dynamic light scattering (Malvern Zetasizer ZS9, Worcestershire, UK).

\section{Cell cultures}

A human neuroblastoma cell line (SH-SY5Y) was obtained from American Type Culture Collection (Rockville, MD). The cells were grown in a complete culture medium consisting of a 1:1 mixture of Hams F12 (Lonza, Milan, Italy), Dulbecco's Modified Eagle's Medium (DMEM) supplemented with $10 \%$ heat-inactivated fetal bovine serum (Lonza), L-glutamine $2 \mathrm{mM}$, penicillin $100 \mathrm{IU} / \mathrm{mL}$, and streptomycin $100 \mu \mathrm{g} / \mathrm{mL}$.

Bone marrow cells were collected from the tibia and femur of Wistar Furth rats following the Dobson procedure. ${ }^{19}$ Mesenchymal stem cells were cultured in DMEM $85 \%$, with $10 \%$ heatinactivated fetal bovine serum, L-glutamine $2 \mathrm{mM}$, penicillin $100 \mathrm{IU} / \mathrm{mL}$, streptomycin $100 \mu \mathrm{g} / \mathrm{mL}$, and gentamicin $0.5 \%$.

Osteogenic differentiation was achieved by culturing mesenchymal stem cells in DMEM supplemented with ascorbic acid $100 \mu \mathrm{g} / \mathrm{mL}$, beta glycerol phosphate $10 \mathrm{mM}$, and dexamethasone $10^{-7} \mathrm{M}$ for 14 days. In all experiments, mesenchymal stem cells were used at passage number 10-12. Cells were maintained at $37^{\circ} \mathrm{C}$ in a saturated humidity atmosphere containing $95 \%$ air with $5 \% \mathrm{CO}_{2}$.

\section{MTT and WST-I assays}

3-(4,5-dimethylthiazole-2-yl)-2,5-diphenyl tetrazolium bromide (MTT) and 2-(4-iodophenyl)-3-(4-nitophenyl)5-(2,4-disulfophenyl)-2H tetrazolium salt (WST-1) cell proliferation assays (BioVision, Mountain View, CA) were used to investigate the effect of zinc oxide nanoparticles and the surfactant on cell viability.

For the MTT assay, $25 \times 10^{3}$ cells were seeded into each well of a 96-well plate and incubated with culture medium overnight. The medium was then replaced with fresh medium containing zinc oxide nanoparticles. After incubation, the nanoparticle-modified medium was replaced with $100 \mu \mathrm{L}$ of medium containing MTT $0.5 \mathrm{mg} / \mathrm{mL}$, and the cells were incubated for 3 hours at $37^{\circ} \mathrm{C}$ and $5 \% \mathrm{CO}_{2}$. The medium containing MTT was then replaced with $100 \mu \mathrm{L}$ of dimethylsulfoxide (Sigma) and left for 10 minutes on a platform shaker to solubilize the converted formazan. The absorbance was measured on a Versamax microplate reader (Molecular Devices, Sunnyvale, CA) at a wavelength of $570 \mathrm{~nm}$ with background subtracted at $690 \mathrm{~nm}$.

For the WST- 1 assay, $25 \times 10^{3}$ cells were seeded into each well of a 96-well plate and incubated overnight. The medium was then replaced with fresh medium containing zinc oxide nanoparticles. After incubation, the cells were added to $10 \mu \mathrm{L}$ of WST-1 solution and incubated for 2 hours. Absorbance was measured using the Versamax microplate reader at a wavelength of $450 \mathrm{~nm}$ with a reference wavelength $650 \mathrm{~nm}$. The results of all assays were expressed as a percentage of the control assays (ie, cells incubated with normal growth medium).

\section{Production of reactive oxygen species}

SH-SY5Y cells were seeded into a 24-well plate and incubated overnight. The cells were then incubated in growth medium modified with zinc oxide nanoparticles $(15 \mu \mathrm{g} / \mathrm{mL})$ for 6 hours. Production of reactive oxygen species was detected using the Image-IT green reactive oxygen species detection kit (Invitrogen, Milan, Italy). The assay is based on 5-(and-6)-carboxy-2', 7'-dichlorodihydrofluorescein diacetate (H2DCFDA), a fluorogenic marker for reactive oxygen species in viable cells. ${ }^{20}$ Tert-butyl hydroperoxide (Invitrogen) was used as a positive control. ${ }^{21}$ A negative control was performed with SH-SY5Y cells cultured in normal growth medium. 
A

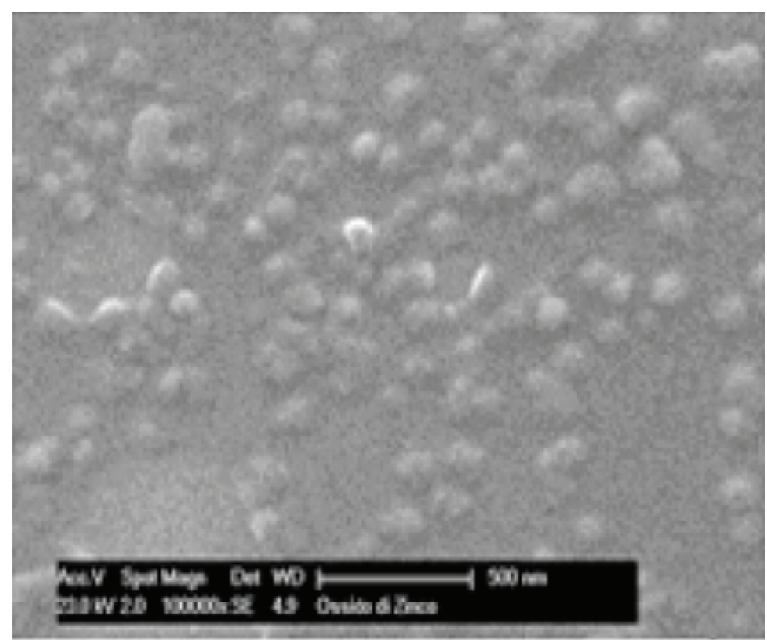

B

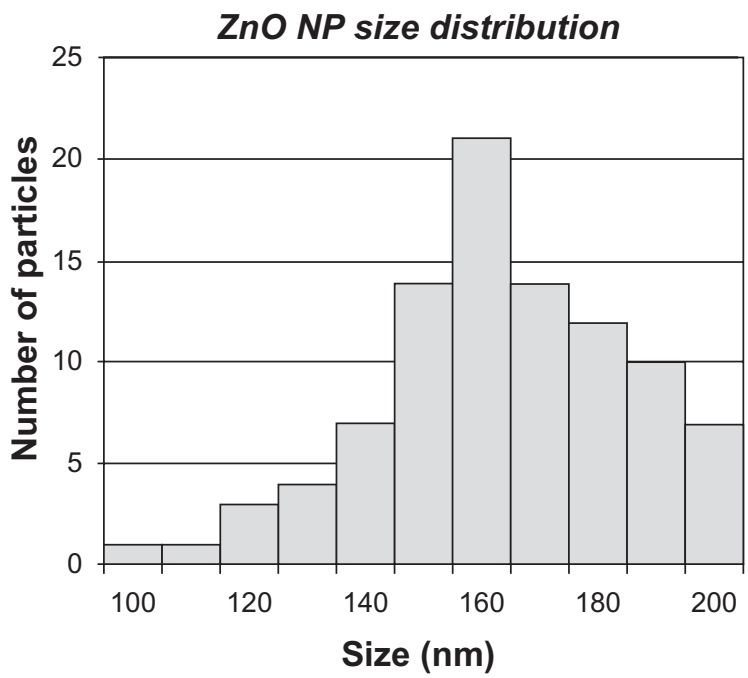

Figure I (A) Scanning electron microscope image of monodispersed zinc oxide nanoparticles. (B) Size distribution of zinc oxide nanoparticles.

\section{Flow cytometry}

Mesenchymal stem cells or osteocytes $\left(500 \times 10^{3}\right)$ were incubated for 6 hours in cell culture medium modified with zinc oxide nanoparticles $(20 \mu \mathrm{g} / \mathrm{mL})$. Cell death was evaluated by propidium iodide (81845 Sigma, Milan, Italy) staining. Results were expressed as a percentage of cell death over the total cell number. Measurement was carried out by a BD FACScan flow cytometer (BD Bioscience, San Jose, $\mathrm{CA})$. The data were acquired and analyzed with CellQuest software. Before acquisition, adherent cells were washed with phosphate-buffered saline, detached by trypsinization, and suspended in measuring buffer containing propidium iodide $50 \mu \mathrm{M}$. A blank (cells incubated with normal cell culture medium) was first used as a reference for adjusting the voltage controlling forward scatter and side scatter.

\section{Modeling}

Mathematical modeling was performed using an algorithm in a MATLAB working space (MATLAB software, version R14).

\section{Statistical analysis}

Results are expressed as mean \pm standard error. Statistical significance was assessed by one-way analysis of variance. Significance was set at $P<0.001$.

\section{Results}

\section{Zinc oxide nanoparticle dispersion}

Aqueous solutions containing zinc oxide nanoparticles were examined after preparation in order to assess the quality of the dispersion. Spectrophotometric analysis was performed at a wavelength of $380 \mathrm{~nm}^{18,22,23}$ showed that among the tested reagents (Arabic gum, polyethylene glycol $8 \mathrm{kDa}$, polyethylene glycol $14 \mathrm{kDa}$, poly(ethylenimine), polyvinyl alcohol, gelatin, Pluronic PF127, sodium dodecyl sulfate, glycine, horse serum, and bovine serum albumin), only Arabic gum produced a stable and highly concentrated dispersion (Table 1). This dispersion was thus chosen for further investigation and biological assays.

The stability of this dispersion was tested for up to 5 days. The dispersion remained stable for 10 hours after preparation (decrease of concentration $<10 \%$ ). The size distribution of the nanoparticles is shown in Figure 1. Electron imaging confirmed that the nanoparticles were singly dispersed (inset of Figure 1) with a size of $160 \pm 60 \mathrm{~nm}$. Figure 2 shows the energy dispersive spectroscopy spectrum of the nanoparticles. The peaks at 0.53 and $0.995 \mathrm{keV}$ are those of oxygen and zinc, respectively. The peak referring to $\mathrm{Si}$ is due to the substrate on which the sample was deposited.

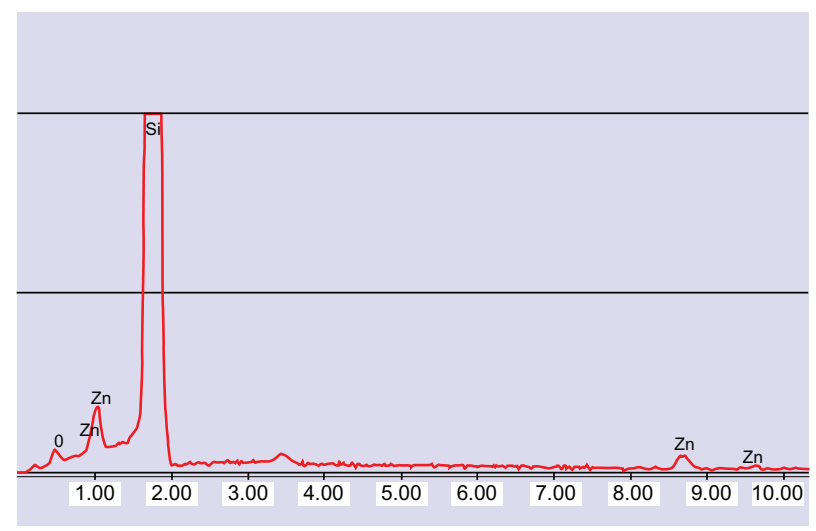

Figure 2 Energy dispersive spectroscopy analysis of zinc oxide nanoparticles. 


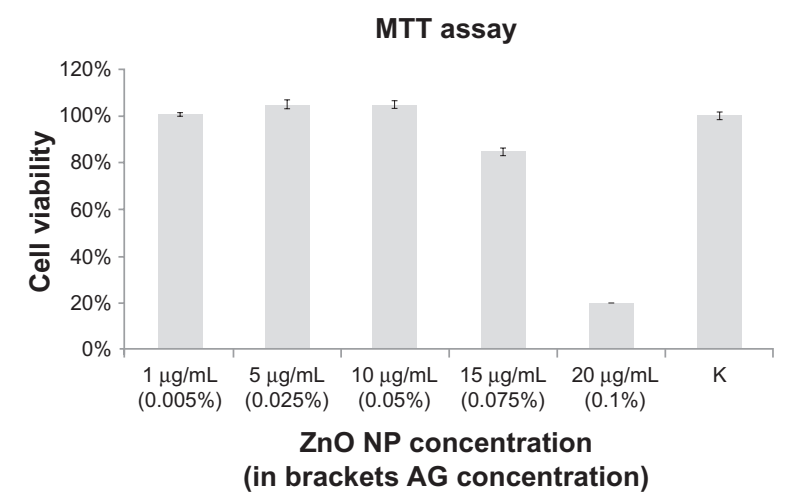

Figure 3 MTT cell proliferation assays of SH-SY5Y cells incubated for 24 hours with different concentrations of zinc oxide nanoparticles (mean \pm standard error, $n=6$ ).

Stability of the dispersion in biological media was tested by dynamic light scattering. Nanoparticles dispersed in phosphate-buffered saline and DMEM showed a size of $286.4 \pm 63.2 \mathrm{~nm}$ and $214.2 \pm 27.70 \mathrm{~nm}$, respectively.

\section{Cytotoxicity}

MTT and WST-1 assays were used to detect the viability of cells by measuring formation of a formazan product as an index of cellular mitochondrial dehydrogenase activity. We selected a neuroblastoma cell line (SH-SY5Y) as a biological model of proliferating cells. As shown in Figure 3, we tested the effect of different zinc oxide nanoparticle concentrations on cell proliferation activity. SHSY5Y cells were incubated with the nanoparticle-modified medium for 24 hours. This was achieved by diluting the initial zinc oxide dispersion (nanoparticle concentration $100 \mu \mathrm{g} / \mathrm{mL}$, Arabic gum concentration $5 \mathrm{mg} / \mathrm{mL}$ ) in cell growth medium.

MTT data confirmed that, with concentrations up to $10 \mu \mathrm{g} / \mathrm{mL}$, no cell damage was observed in any of the tested samples. However, an $85 \%$ decrease in cell viability was observed when the concentration of zinc oxide nanoparticles was increased to $15 \mu \mathrm{g} / \mathrm{mL}$. The toxic effects became more

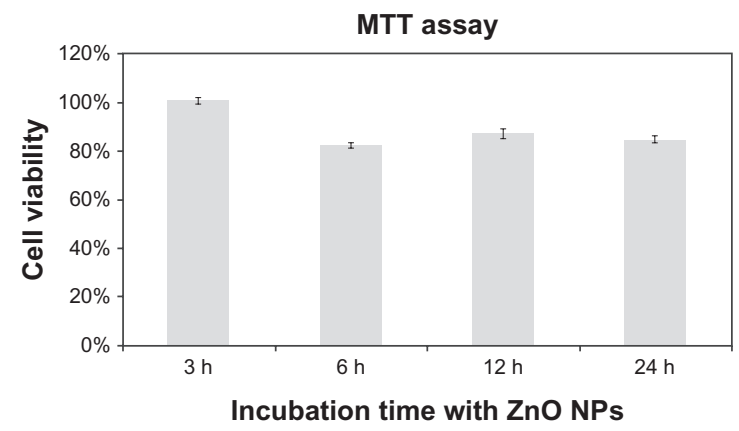

Figure 4 MTT cell proliferation assays of SH-SY5Y cells at different incubation times with a concentration of $15 \mu \mathrm{g} / \mathrm{mL}$ (mean \pm standard error, $\mathrm{n}=6$ ). evident (cell viability approaching $20 \%$ ) when the concentration of nanoparticles was increased to $20 \mu \mathrm{g} / \mathrm{mL}$. In sharp contrast, Arabic gum did not alter cell viability at any concentration tested (data not shown). Cell proliferation assay was also performed with a WST-1 kit, which confirmed the results seen in Figure 3 (data not shown).

We estimated cell viability at different incubation times in order to gather information on the dynamics of the cytotoxicity induced by the nanoparticles. Specifically, we incubated SH-SY5Y for 3, 6, 12, and 24 hours with cell culture medium modified with zinc oxide nanoparticles at a concentration of $15 \mu \mathrm{g} / \mathrm{mL}$ (Figure 4). These experiments demonstrated that the toxic effects become apparent at 3-6 hours of incubation with the nanoparticles.

Published reports have demonstrated that zinc oxide nanoparticles induce formation of excess reactive oxygen species resulting in alteration and damage of cellular proteins, DNA, and lipids, which can cause cell death. ${ }^{24-27}$ We used carboxy-H2DCFDA fluorescence as a reporter of intracellular oxidant production. To study the effect of zinc oxide nanoparticles on the induction of reactive oxygen species in SH-SY5Y cells, we selected a dose known to affect cell viability (Figures 3 and 4). Specifically, we incubated the cells with $15 \mu \mathrm{g} / \mathrm{mL}$ of the nanoparticles for 6 hours. As shown in Figure 5, the nanoparticles produced an increase in reactive oxygen species similar to that in the positive control.

\section{Finite element analysis}

On the basis of a mathematical model suggested by Jin et $a l,{ }^{28}$ an algorithm was developed in a MATLAB workspace which predicts the dynamics of zinc oxide nanoparticle internalization. In this model, nanoparticle internalization is described by an interconnected kinetic model able to determine transport rates in the various cellular compartments. Zinc oxide nanoparticles are presumed to be coated by extracellular proteins and to bind to cellular receptors. Adsorbed complexes are thus internalized via receptor-mediated endocytosis. Specifically, nanoparticles (concentration $L$ ) are adsorbed on the cell membrane by cell surface receptors, $R_{s}, K_{f}$, and $K_{r}$, being forward and reverse kinetic rates. This causes the surface nanoparticle concentration on the membrane $C_{s}$ to increase. The absorbed nanoparticles are then endocytosed in lysosomes (kinetic rates $K_{e}$ ) and can be recycled back to the plasma membrane with a rate constant of $K_{\text {rec }} . C_{i}$ represents the molar zinc concentration inside the lysosome. The equations describing the internalization process are: 
A
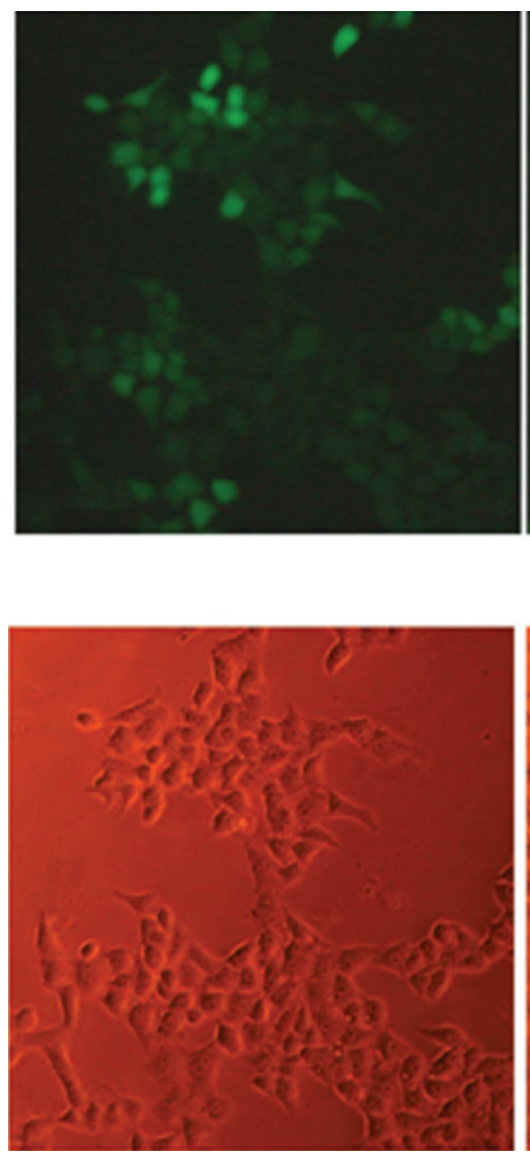

B
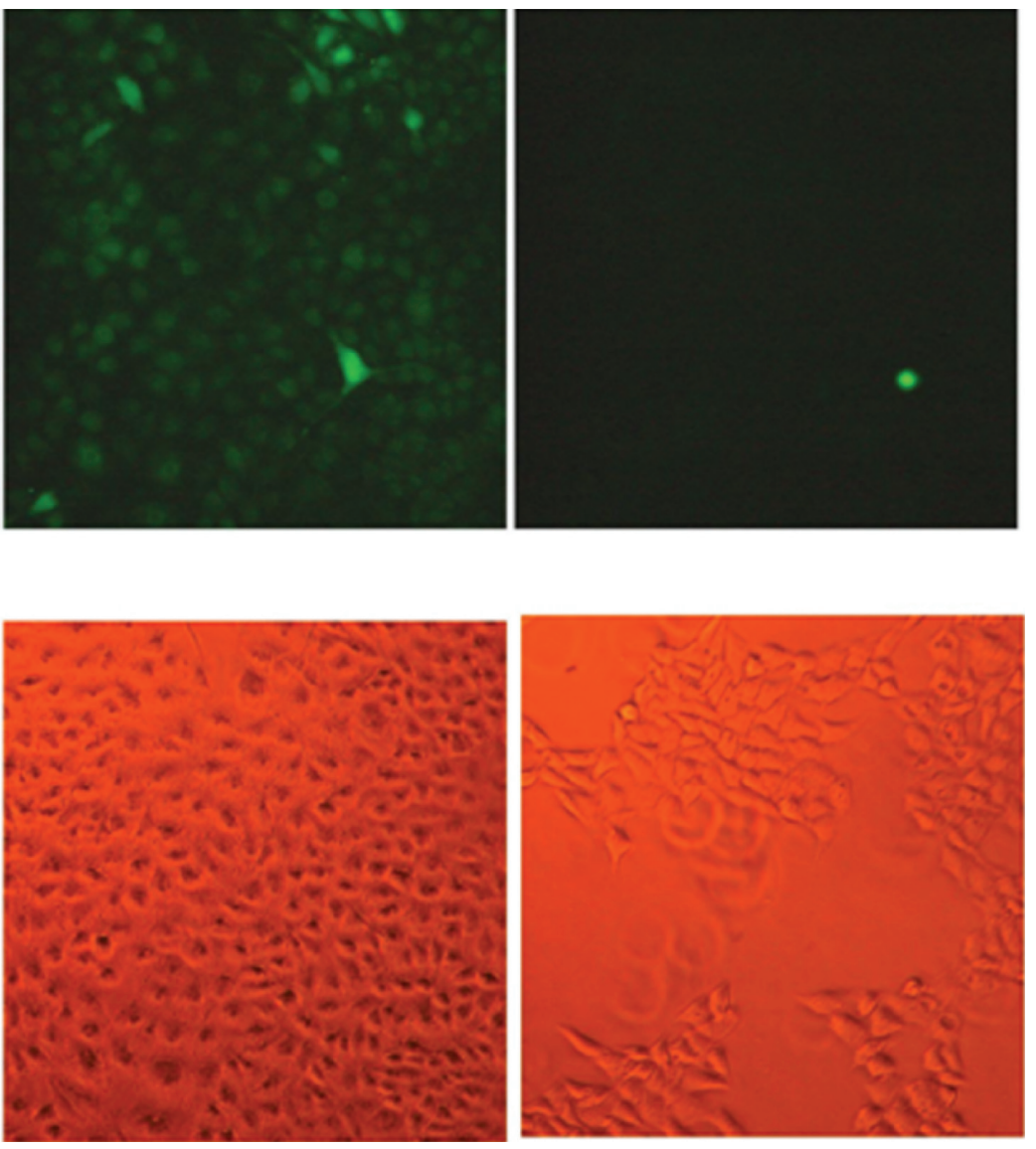

Figure 5 Detection of intracellular reactive oxygen species in (A) SH-SY5Y treated with tert-butyl hydroperoxide, a common inducer of reactive oxygen species (positive control), (B) SH-SY5Y treated with zinc oxide nanoparticle-modified culture medium ( $15 \mu \mathrm{g} / \mathrm{mL})$, (C) SH-SY5Y treated with culture medium added with Arabic gum 0.075\%. Top images: oxidative stress is represented by green fluorescent cells. Bottom images: bright field. $(\mathrm{n}=3)$. Scale bar: $10 \mu \mathrm{m}$.

$$
\begin{gathered}
\frac{d L}{d t}=\left(k_{f} \times L \times R_{s}+k_{r} \times C_{s}\right) \times\left(\frac{n}{N}\right) \\
\frac{d C_{s}}{d t}=k_{f} \cdot L \cdot R_{s}-\left(k_{r}+k_{e}\right) \cdot C_{s}+k_{r e c} \cdot C_{i} \\
\frac{d C_{i}}{d t}=k_{e} \times C_{s}+k_{r e c} \times C_{i}
\end{gathered}
$$

where $n$ represents cell density (cells/L) and $N$ is Avogadro's number. For convenience, parameters can be grouped and simplified:

$$
\begin{gathered}
\frac{d L}{d t}=-k_{a} \cdot L+k_{r} \cdot C_{s} \\
\frac{d c_{s}}{d t}=k_{a} \cdot L-\left(k_{r}+k_{e}\right) \cdot C_{s}+k_{r e c} \cdot c_{i} \\
\frac{d c_{i}}{d t}=k_{e} \times C_{s}+k_{r e c} \times c_{i}
\end{gathered}
$$

where

$$
\begin{gathered}
k_{a}=k_{f} \times R_{s 0} \times\left(\frac{n}{N}\right) \\
c_{s}=C_{s} \times\left(\frac{n}{N}\right) \\
c_{i}=C_{i} \times\left(\frac{n}{N}\right)
\end{gathered}
$$

and $R_{s 0}$ is the initial surface receptor density. Model parameter values were found in literature: 28

$$
\begin{gathered}
k_{r}=0.34 \mathrm{~min}^{-1} \\
k_{f}=7.2 \times 10^{7} M^{-1} \mathrm{~min}^{-1} \\
k_{e}=1.14 \times 10^{-6} \mathrm{~min}^{-1} \\
k_{\text {rec }}=0.005 \mathrm{~min}^{-1}
\end{gathered}
$$




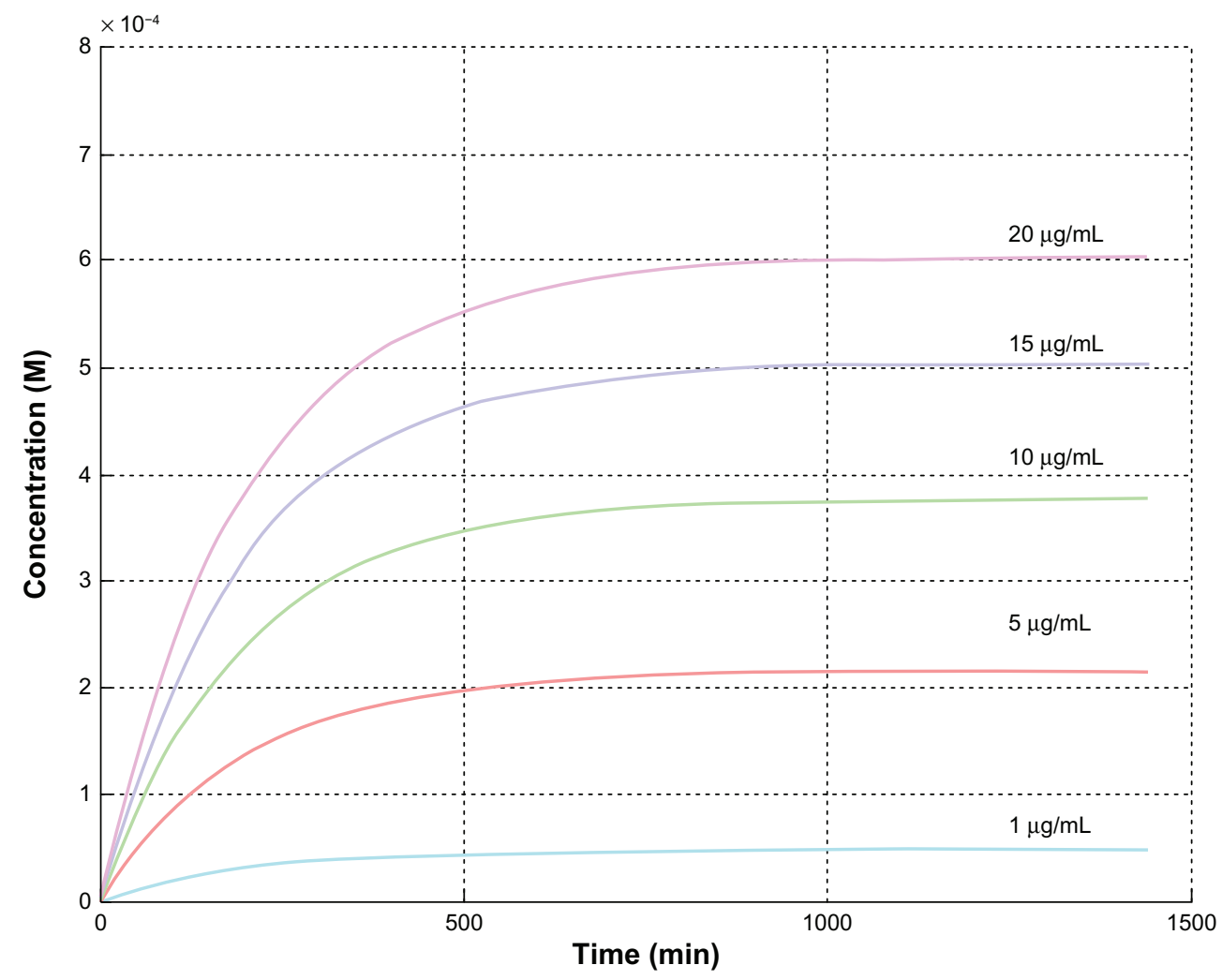

Figure 6 Prediction of the intracellular concentration, $\mathrm{Ci}(\mathrm{M})$, versus time for the different $\mathrm{ZnO}$ NP concentrations by mathematical modeling.

Initial receptor density, $R_{s 0}$, of SH-SY5Y cells had been previously established as $4 \times 10^{4} .{ }^{29}$ In our experimental conditions, the cellular density, $\mathrm{n}$, is $25 \times 10^{3} / L_{0}$; cytosolic and lysosomal concentrations of zinc are $1 \times 10^{-10} \mathrm{M}$ and $1 \times 10^{-4} \mathrm{M}$, respectively. ${ }^{28}$

Implementation of the previous equations in a MATLAB workspace allowed estimation of the intracellular concentration, $c_{i}$, versus time for the different zinc oxide nanoparticle concentrations used in the cell growth medium (Figure 6).

\section{Flow cytometry}

Our experiments confirmed that in a biological model of proliferating cells, zinc oxide nanoparticles induced cytotoxicity through a mechanism involving production of reactive oxygen species. In the following experiment, we investigated if this behavior was cell-specific and proliferation-dependent, as previously suggested for normal and cancerous $\mathrm{T}$ cells. ${ }^{14,16}$ We selected highly proliferating mesenchymal stem cells as the biological model. The advantage of this choice is that mesenchymal stem cells can be easily differentiated into quiescent osteocytes (G0). We used flow cytometry to analyze the interaction of the zinc oxide nanoparticles with mesenchymal stem cells and osteocytes. Consistent with previous work, the cells were incubated with the nanoparticles at $20 \mu \mathrm{g} / \mathrm{mL}$ for 6 hours. As expected, the nanoparticles adversely affected the viability of the mesenchymal stem cells but not that of osteocytes, which showed viability similar and not statistically significantly different from that of the control cultures (Figures 7 and 8).

\section{Discussion}

Here we report a simple procedure for obtaining a stable biocompatible monodispersion of zinc oxide nanoparticles in Arabic gum. Arabic gum is a natural composite polysaccharide largely used to coat several kinds of nanoparticles..$^{30}$ Spectrophotometric analysis revealed that the concentration of nanoparticles approached $100 \mu \mathrm{g} / \mathrm{mL}$ and decreased slowly over time. We estimate that the stability of the dispersion is 10 hours (decrease of nanoparticle concentration below 10\%). The mechanism of nanoparticle dispersion involves rupture of Van der Waals forces between nanoparticles. The underlying principle is that the surfactant molecules adsorb on the surface of the particles by virtue of their amphiphilic nature. In particular, the hydrophobic part of these molecules is chemisorbed on the nanoparticle outer 

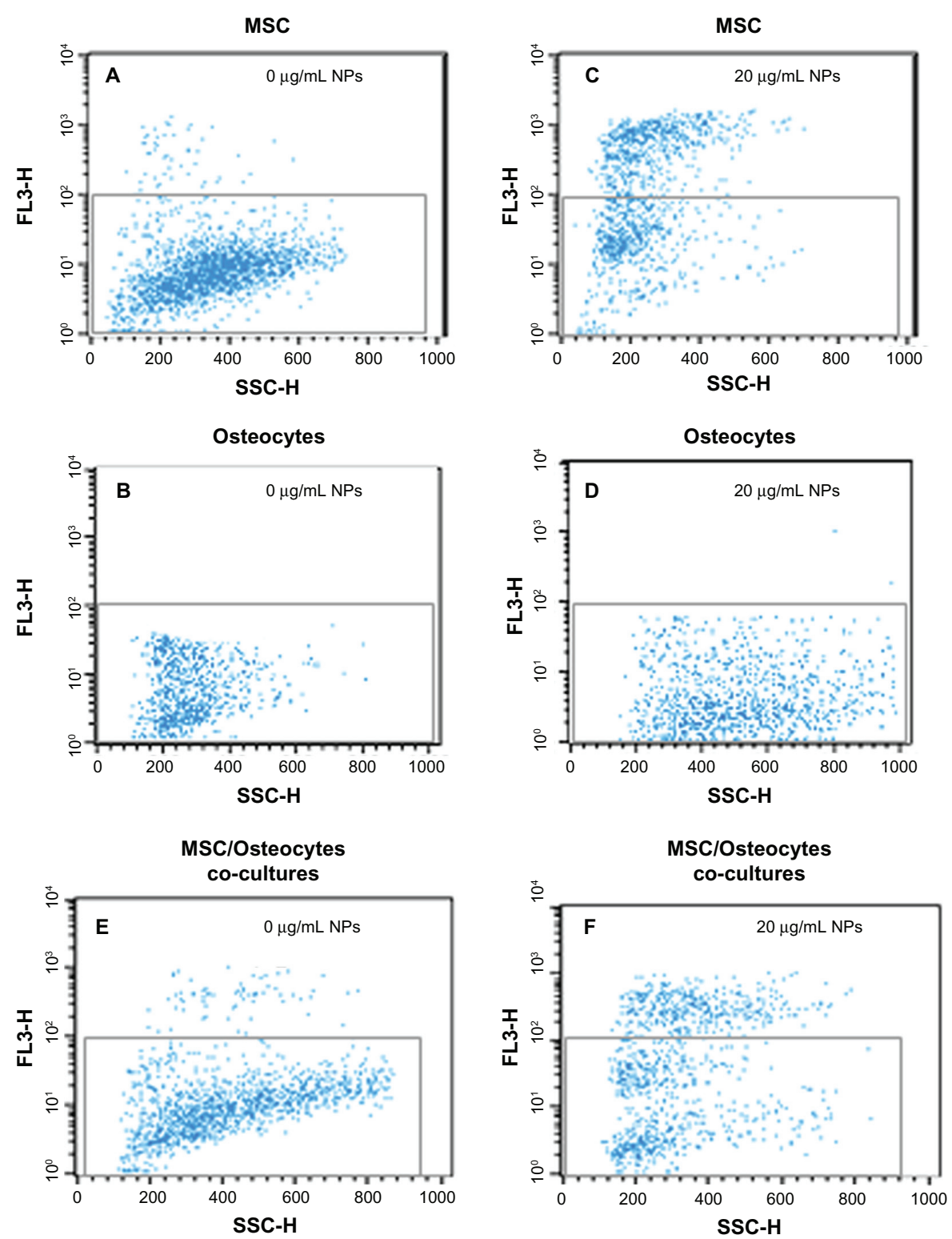

Figure 7 Flow cytometry. (A) Mesenchymal stem cells cultured in cell culture medium modified with zinc oxide nanoparticles. (B) Mesenchymal stem cells cultured in cell culture medium. (C) Osteocytes cultured in cell culture medium modified with zinc oxide nanoparticles. (D) Osteocytes cultured in cell culture medium. (E) Mesenchymal stem cells and osteocytes cocultured in cell culture medium modified with zinc oxide nanoparticles. (F) Mesenchymal stem cells and osteocytes cocultured in cell culture medium. (Zinc oxide nanoparticle concentration $20 \mu \mathrm{g} / \mathrm{mL}$; incubation time six hours).

surface and these reduce the Van der Waals forces between the particles, rendering them soluble in aqueous media. The mechanism which avoids nanoparticle reaggregation in Arabic gum solution is probably steric. Electron imaging performed on a drop of dispersion, after drying, revealed that the nanoparticles are singly dispersed, and Arabic gum coating increases the nanoparticle diameter by about $10 \mathrm{~nm}$ (Figure 1). Additionally, energy dispersive spectroscopy microanalysis confirmed that the dispersion treatment did not alter nanoparticle chemistry (Figure 2). Dynamic light scattering analysis performed on zinc oxide nanoparticles in biological media (phosphate-buffered saline and DMEM) confirmed that the particles were still well dispersed, but the size of the AG nanoparticles was notably larger than that of the dried particles (220-280 $\mathrm{nm}$ and $160 \mathrm{~nm}$, respectively). This size may be attributed to the Arabic gum chain attaching to the nanoparticle in a hydrated conformation.

Zinc oxide nanoparticle dispersions have already been used for cytotoxicity studies. Some published reports indicate that zinc oxide nanoparticles can be toxic to mammalian cells. ${ }^{5-7}$ Hanley et al proposed that the mechanism of zinc oxide nanoparticle toxicity involves the generation of reactive 


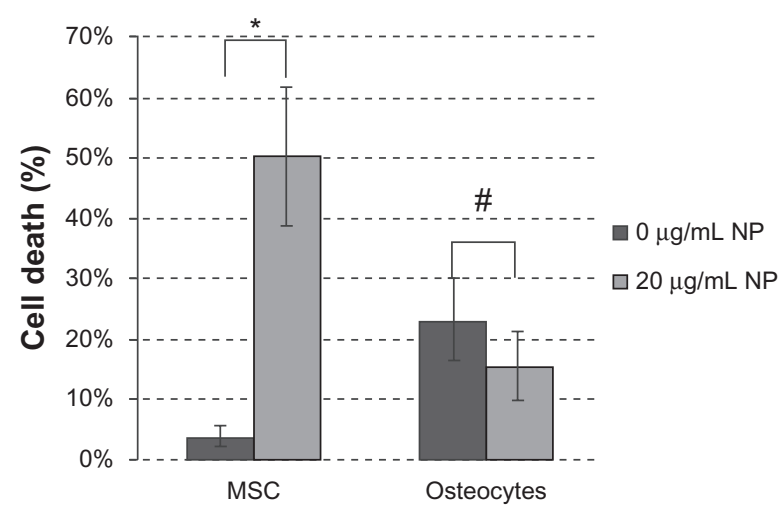

Figure 8 Zinc oxide nanoparticle toxicity in mesenchymal stem cells versus osteocytes. Cultures were treated with zinc oxide nanoparticles for 6 hours and cell viability was determined using flow cytometry and propidium iodide uptake (mean \pm standard error, $n=4)$.

oxygen species. These authors also suggested cell-specific behavior, with cancer cells producing higher inducible levels of reactive oxygen species than their normal counterparts following exposure to zinc oxide nanoparticles. ${ }^{17}$

Our cell proliferation assays performed in a human neuroblastoma cell line demonstrate that the cytotoxicity induced by zinc oxide nanoparticles is dose-dependent (Figure 3). We observed no significant changes in cell viability of nanoparticle concentrations of $10 \mu \mathrm{g} / \mathrm{mL}$. At these concentrations, we observed a spurious small increase in viability compared with the control due to nanoparticle absorbance at the working wavelength. Cell viability dropped significantly at a nanoparticle concentration of $20 \mu \mathrm{g} / \mathrm{mL}$, and was associated with production of reactive oxygen species (Figure 5).

Based on published work and our own findings, we have developed a model of zinc oxide nanoparticle cytotoxicity. Essentially the process involves internalization of the nanoparticles via receptor-mediated endocytosis, hydrolysis of the nanoparticles via zinc ions within the lysosomes, and release of zinc ions into the cytosol (Figure 9).

When zinc oxide nanoparticles are added to growth medium, the particles are coated by proteins in the medium. Cell surface receptors bind the protein adsorbed onto the nanoparticles, and the nanoparticles enter cells via receptor-mediated endocytosis. When nanoparticlecontaining endosomes fuse with lysosomes, the $\mathrm{pH}$ drops dramatically, approaching 5. The inset of Figure 9 shows the rate of zinc oxide hydrolysis as a function of $\mathrm{pH}$; whereas under physiological conditions the fraction hydrolyzed is negligible $(0.02 \%)$, the hydrolysis of zinc oxide is complete at $\mathrm{pH} 5.75$. The zinc ions induce lysis of the lysosomal membrane, and

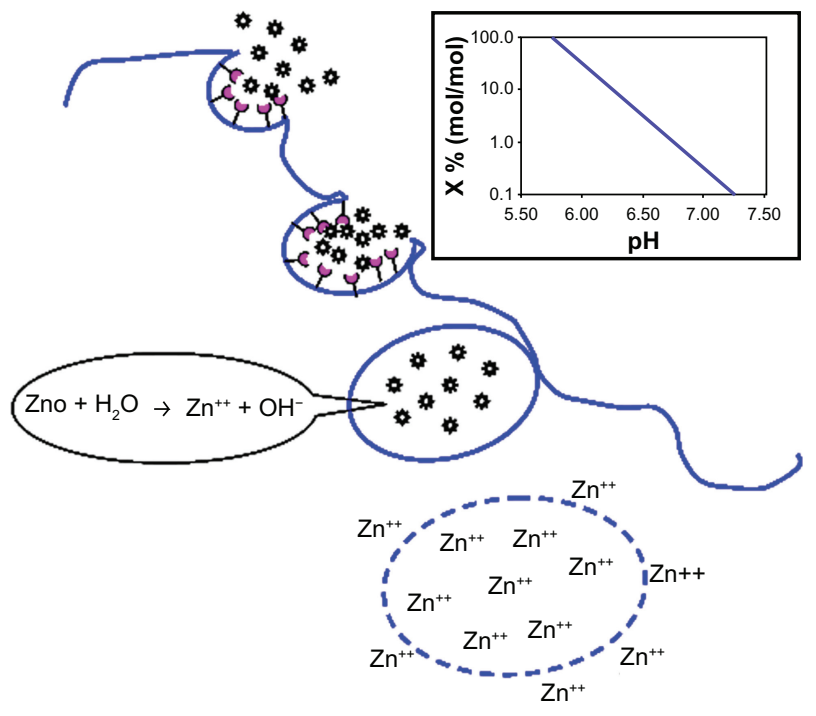

Figure 9 Schematic model of zinc oxide nanoparticle cytotoxicity. Inset: $\mathrm{pH}$-dependent hydrolysis of zinc oxide.

the ions are released into the cytosol. Cytosolic accumulation of zinc ions triggers pathways which ultimately cause cell death. Specifically, Xia et al demonstrated that zinc oxide dissociation disrupts the cellular homeostasis of zinc, leading to lysosomal and mitochondrial damage, and ultimately cell death by inhibiting cellular respiration through interference with cytochrome bc 1 in complex III and with $\alpha$-ketoglutarate dehydrogenase in complex I. ${ }^{24}$ Other researchers have underlined that zinc ion-mediated production of reactive oxygen species promotes two important mechanisms, ie, cytoplasmic release of calcium ions and interaction with the cytoplasmic membrane, causing loss of membrane integrity and leading to calcium influx through membrane channels. ${ }^{25}$

Table I Dispersion of zinc oxide nanoparticles

\begin{tabular}{|c|c|c|c|c|}
\hline Reagent & $\begin{array}{l}\text { Reagent } \\
\text { concentration }\end{array}$ & $\begin{array}{l}\text { Dispersion } \\
\text { method' }^{\prime}\end{array}$ & Pellet' & $\begin{array}{l}\text { NP } \\
\text { concentration } \\
(\mu \mathrm{g} / \mathrm{mL})\end{array}$ \\
\hline PEG $8 \mathrm{~K}$ & $5 \%$ & US & $Y$ & - \\
\hline PEG I4 K & $5 \%$ & US & $Y$ & - \\
\hline PEI & $5 \%$ & US & $\mathrm{N}$ & - \\
\hline PA & $5 \%$ & US & $Y$ & - \\
\hline Gelatin & $5 \%$ & US & $Y$ & - \\
\hline PF I 27 & $5 \%$ & US & $Y$ & 10 \\
\hline SDS & $5 \%$ & US & $Y$ & - \\
\hline AG & $5 \%$ & US & $\mathrm{N}$ & 100 \\
\hline GLY & $5 \%$ & US & $N$ & - \\
\hline $\mathrm{HS}$ & $5 \%$ & MS & $Y$ & - \\
\hline BSA & $5 \%$ & MS & $Y$ & - \\
\hline
\end{tabular}

Note: 'After centrifugation at $900 \mathrm{~g}$.

Abbreviations: US, sonication; MS, magnetic stirring; PEG, polyethylene glycol; PEI, poly(ethylenimine); PA, polyvinyl alcohol; PF, Pluronic ${ }^{\circledR}$; SDS, sodium dodecyl sulfate; AG, Arabic gum; GLY, glycine; HS, horse serum; BSA, bovine serum albumin. 
The physiological zinc ion concentration in the cytosol ranges from $10^{-9}$ to $10^{-12} \mathrm{mM}$, whereas the zinc ion concentration in lysosomes is about $10^{-4} \mathrm{mM}$. Figure 6 shows the cytosolic concentration of zinc ions with time for different initial concentrations of zinc oxide nanoparticles in growth medium. For all curves, the cytosolic concentration of zinc ions reaches a plateau within 6 hours of incubation, in agreement with experimental observations (Figure 4).

Figure 5 shows that cell viability starts to decline after 24 hours of continuous incubation with zinc oxide nanoparticles at concentrations of $10-15 \mu \mathrm{g} / \mathrm{mL}$, corresponding to intracellular zinc ion levels of $0.38-0.5 \mathrm{mM}$ (Figure 6). Additionally, when cells are incubated with zinc oxide nanoparticles at a concentration of $15 \mu \mathrm{g} / \mathrm{mL}$, a decrease in cell viability is observed within 3 and 6 hours of incubation, the intracellular zinc ion concentration being $0.3 \mathrm{mM}$ and $0.42 \mathrm{mM}$, respectively (Figure 6). From coupling the previous values, we obtained: $\{0.38 ; 0.5\} \cap\{0.3 ; 0.42\}=\{0.38 ; 0.42\}$.

The threshold value of intracellular zinc oxide nanoparticles (ie, zinc ion concentration) for induction of cell death is thus $0.4 \pm 0.02 \mathrm{mM}$. This information is applicable in principle to a biological model of proliferating cells. What about noncancerous cells? And more interestingly, what happens if the cell changes its proliferation rate? We addressed this question in the last part of the study in which we used a natural model of undifferentiated mesenchymal stem cells derived from bone marrow with the capacity to replicate and differentiate in vitro into several lineages including bone, cartilage, stroma, fat, muscle, and tendon. The therapeutic potential of mesenchymal stem cells in cell therapy for several incurable or debilitating disorders has generated considerable interest in the field of regenerative medicine. ${ }^{31}$ Over the last two decades, mesenchymal stem cell-based therapy has progressed rapidly from preclinical to early clinical Phase I and II studies in a range of human diseases (www.clinicaltrialgov). Osteocytes used in this work were obtained via osteogenic differentiation of mesenchymal stem cells. These two populations, although biologically related, show opposite proliferation rates. We evaluated cell death induced by zinc oxide nanoparticles using flow cytometry (Figures 7 and 8). In flow cytometry, a single wavelength laser beam illuminates each cell and generates forward scatter and side scatter signals. Forward scatter correlates with cross-sectional cell area and side scatter reflects intracellular complexity, such as membrane roughness, nucleus shape, and the amount of cytoplasmic granules. Hence, flow cytometry is a powerful tool for investigating the interaction between nanoparticles and cells. ${ }^{32}$ The effect of zinc oxide nanoparticles on plasma membrane damage was assessed by permeability to propidium iodide. Cells were incubated with $20 \mu \mathrm{g} / \mathrm{mL}$ of zinc oxide nanoparticles for 6 hours (corresponding to an intracellular zinc concentration of $0.5 \mathrm{mM}$ ). We analyzed three experimental groups, ie, mesenchymal stem cells (Figures 7A and 7B), osteocytes (Figures 7C and 7D), and mesenchymal stem cells/osteocyte cocultures (Figures 7E and 7F). The experimental data obtained with the mesenchymal stem cells confirmed the behavior previously observed with human neuroblastoma cells, ie, zinc oxide nanoparticles induced cytotoxicity at a certain dosage (Figure 8). The same dose of zinc oxide nanoparticles added to cultured osteocytes did not induce any significant cytotoxic effects (Figure 8). Again, the cytotoxicity observed in cocultures seems to overlap with the data acquired independently for each single culture (Figures 7B, 7D, and 7F). In conclusion, the increased fluorescent intensity in the presence of zinc oxide nanoparticles was more significant in mesenchymal stem cells than in the differentiated osteogenic lineage. The different behavior of the two cell types is likely due to the different cellular interaction with zinc oxide nanoparticles rather than to any differences in uptake of the nanoparticles. The strong interaction between osteocytes and the nanoparticles is reflected by the parallel strong increase of side scatter compared with the control cultures, indicative of increased cellular complexity due to nanoparticle-cell interaction. ${ }^{32}$ It has been reported that nanomaterials can promote autophagy, ${ }^{33-36}$ and this could be an alternative biological process altering the side scatter profile. Because autophagy ultimately causes cell death, the negligible cytotoxicity induced by zinc oxide nanoparticles on osteocytes (Figure 8) suggests that the alteration in side scatter could be a result of interaction with the nanomaterials rather than an autophagic process.

Our findings are thus in agreement with the hypothesis that the mechanisms of zinc oxide nanoparticle toxicity might be related to the proliferative potential of the cell. ${ }^{14,16}$ The explanation of this lies in the extent of production of reactive oxygen species mediated by zinc oxide nanoparticles, this being much higher in rapidly pluripotential proliferating cells than in differentiated cells. Based on this findings, we confirm that zinc oxide nanoparticles have the potential to function as natural selective killers of all highly proliferating cells, whether cancerous or not. In conclusion, although the application of zinc oxide nanoparticles in cancer therapy looks intriguing and exciting, specific tumor cell targeting will be essential (eg, by 
nanoparticle functionalization with cell ligands) because these nanoparticles are killers of all rapidly proliferating cells, irrespective of their benign or malignant nature.

\section{Acknowledgments}

The authors thank Mr Carlo Filippeschi from the Center of Reseach in Microengineering (CRIM) Laboratory of Scuola Superiore Sant'Anna for his contribution to the electron imaging and Dr Valerio Voliani from the Italian Institute of Technologies (IIT)@NEST, the Center for Nanotechnology Innovation, for the use of dynamic light scattering. This work was partially supported by the Magnetic Nanoparticle for Nerve Regeneration NanoSci-E+2008 project, cofounded by European Commission (EC) / Consiglio Nazionale delle Ricerche (CNR), and by the NanoDiab-1 project cofounded by Fondazione Cassa di Risparmio di Pisa.

\section{Disclosure}

The authors report no conflicts of interest in this work.

\section{References}

1. Bai XD, Gao PX, Wang ZL, Wang EG. Dual-mode mechanical resonance of individual $\mathrm{ZnO}$ nanobelts. Appl Phys Lett. 2003;82(26): 4806-4808.

2. Zhang LL, Jiang YH, Ding YL, et al. Mechanistic investigation into antibacterial behaviour of suspensions of $\mathrm{ZnO}$ nanoparticles against E. coli. J Nanopart Res. 2010;12(5):1625-1636.

3. Huang ZB, Zheng X, Yan DH, et al. Toxicological effect of ZnO nanoparticles based on bacteria. Langmuir. 2008;24(8):4140-4144.

4. Reddy KM, Feris K, Bell J, Wingett DG, Hanley C, Punnoose A. Selective toxicity of zinc oxide nanoparticles to prokaryotic and eukaryotic systems. Appl Phys Lett. 2007;90(21):2139021-2139023.

5. Jeng HA, Swanson J. Toxicity of metal oxide nanoparticles in mammalian cells. J Environ Sci Health A Tox Hazard Subst Environ Eng. 2006;41(12):2699-2711.

6. Gojova A, Guo B, Kota RS, Rutledge JC, Kennedy IM, Barakat AI. Induction of inflammation in vascular endothelial cells by metal oxide nanoparticles: Effect of particle composition. Environ Health Perspect 2007;115(3):403-409.

7. Deng XY, Luan QX, Chen WT, et al. Nanosized zinc oxide particles induce neural stem cell apoptosis. Nanotechnology. 2009;20(11):115101.

8. Jones N, Ray B, Ranjit KT, Manna AC. Antibacterial activity of ZnO nanoparticle suspensions on a broad spectrum of microorganisms. FEMS Microbiol Lett. 2008;279(1):71-76.

9. Hanley C, Thurber A, Hanna C, Punnoose A, Zhang J, Wingett DG. The influences of cell type and $\mathrm{ZnO}$ nanoparticle size on immune cell cytotoxicity and cytokine induction. Nanoscale Res Lett. 2009;4(12) 1409-1420.

10. Zhao JX, Xu LJ, Zhang T, Ren GG, Yang Z. Influences of nanoparticle zinc oxide on acutely isolated rat hippocampal $\mathrm{CA} 3$ pyramidal neurons. Neurotoxicology. 2009;30(2):220-230.

11. Tang EJ, Cheng GX, Ma XL, Pang XS, Zhao Q. Surface modification of zinc oxide nanoparticle by PMAA and its dispersion in aqueous system. Appl Surf Sci. 2006;252(14):5227-5232.

12. George S, Pokhrel S, Xia T, et al. Use of a rapid cytotoxicity screening approach to engineer a safer zinc oxide nanoparticle through iron doping. ACS Nano. 2010;4(1):15-29.
13. Seil JT, Webster TJ. Decreased astroglial cell adhesion and proliferation on zinc oxide nanoparticle polyurethane composites. Int $J$ Nanomedicine. 2008;3(4):523-531.

14. Hanley C, Layne J, Punnoose A, et al. Preferential killing of cancer cells and activated human $\mathrm{T}$ cells using $\mathrm{ZnO}$ nanoparticles. Nanotechnology. 2008;19(29):295103.

15. Brayner R, Ferrari-Iliou R, Brivois N, Djediat S, Benedetti MF, Fievet F. Toxicological impact studies based on Escherichia coli bacteria in ultrafine $\mathrm{ZnO}$ nanoparticles colloidal medium. Nano Lett. 2006;6(4):866-870.

16. Ostrovsky S, Kazimirsky G, Gedanken A, Brodie C. Selective cytotoxic effect of ZnO nanoparticles on glioma cells. Nano Res. 2009;2(11): 882-890.

17. Wang ZL. Zinc oxide nanostructures: Growth, properties and applications. J Phys Condens Matter. 2004;16(25):R829-R858.

18. Djurisic $\mathrm{AB}$, Leung $\mathrm{YH}$. Optical properties of $\mathrm{ZnO}$ nanostructures. Small. 2006;2(8-9):944-961.

19. Dobson KR, Reading L, Haberey M, Marine X, Scutt A. Centrifugal isolation of bone marrow from bone: An improved method for the recovery and quantitation of bone marrow osteoprogenitor cells from rat tibiae and femurae. Calcif Tissue Int. 1999;65(5):411-413.

20. Maurer BJ, Metelitsa LS, Seeger RC, Cabot MC, Reynolds CP. Increase of ceramide and induction of mixed apoptosis necrosis by $\mathrm{N}-(4-$ hydroxyphenyl)-retinamide in neuroblastoma cell lines. $J$ Natl Cancer Inst. 1999;91(13):1138-1146.

21. Diaz G, Liu SS, Isola R, Diana A, Falchi AM. Mitochondrial localization of reactive oxygen species by dihydrofluorescein probes. Histochem Cell Biol. 2003;120(4):319-325.

22. Yuan D, Wang GS, Xiang Y, Chen Y, Gao XQ, Lin G. Optical properties and formation mechanism of radial $\mathrm{ZnO}$ hexagonal nanoprism clusters. J Alloys Compd. 2009;478(1-2):489-492.

23. Greene LE, Yuhas BD, Law M, Zitoun D, Yang PD. Solution-grown zinc oxide nanowires. Inorg Chem. 2006;45(19):7535-7543.

24. Xia T, Kovochich M, Liong M, et al. Comparison of the mechanism of toxicity of zinc oxide and cerium oxide nanoparticles based on dissolution and oxidative stress properties. ACS Nano. 2008;2(10): 2121-2134.

25. Huang CC, Aronstam RS, Chen DR, Huang YW. Oxidative stress, calcium homeostasis, and altered gene expression in human lung epithelial cells exposed to $\mathrm{ZnO}$ nanoparticles. Toxicol in Vitro. 2010;24(1): $45-55$.

26. Florianczyk B, Trojanowski T. Inhibition of respiratory processes by overabundance of zinc in neuronal cells. Folia Neuropathol. 2009;47(3):234-239.

27. Gazaryan IG, Krasnikov BF, Ashby GA, Thorneley RNF, Kristal BS, Brown AM. Zinc is a potent inhibitor of thiol oxidoreductase activity and stimulates reactive oxygen species production by lipoamide dehydrogenase. J Biol Chem. 2002;277(12):10064-10072.

28. Jin H, Heller DA, Sharma R, Strano MS. Size-dependent cellular uptake and expulsion of single-walled carbon nanotubes: Single particle tracking and a generic uptake model for nanoparticles. ACS Nano. 2009;3(1): 149-158.

29. Raffa V, Vittorio O, Ciofani G, Pensabene V, Cuschieri A. Cell creeping and controlled migration by magnetic carbon nanotubes. Nanoscale Res Lett. 2010;5(1):257-262.

30. Roque ACA, Bicho A, Batalha IL, Cardoso AS, Hussain A Biocompatible and bioactive gum Arabic coated iron oxide magnetic nanoparticles. J Biotechnol. 2009;144(4):313-320.

31. Gerson SL. Mesenchymal stem cells: No longer second class marrow citizens. Nat Med. 1999;5(3):262-264.

32. Cai D, Blair D, Dufort FJ, et al. Interaction between carbon nanotubes and mammalian cells: Characterization by flow cytometry and application. Nanotechnology. 2008;19(34):1-10.

33. Zabirnyk O, Yezhelyev M, Seleverstov O. Nanoparticles as a novel class of autophagy activators. Autophagy. 2007;3(3):278-281. 
34. Li JJ, Hartono D, Ong CN, Bay BH, Yung LY. Autophagy and oxidative stress associated with gold nanoparticles. Biomaterials. 2010;31(23): 5996-6003.

35. Li C, Liu H, Sun Y, et al. PAMAM nanoparticles promote acute lung injury by inducing autophagic cell death through the Akt-TSC2-mTOR signaling pathway. J Mol Cell Biol. 2009;1(1):37-45.
36. Wei P, Zhang L, Lu Y, Man N, Wen L. C60(Nd) nanoparticles enhance chemotherapeutic susceptibility of cancer cells by modulation of autophagy. Nanotechnology. 2010;21(49):495101.

International Journal of Nanomedicine

Dovepress

\section{Publish your work in this journal}

The International Journal of Nanomedicine is an international, peerreviewed journal focusing on the application of nanotechnology in diagnostics, therapeutics, and drug delivery systems throughout the biomedical field. This journal is indexed on PubMed Central, MedLine, CAS, SciSearch ${ }^{\circledR}$, Current Contents ${ }^{\circledR} /$ Clinical Medicine, Elsevier Bibliographic databases. The manuscript management system is completely online and includes a very quick and fair peer-review system, which is all easy to use. Visit http://www.dovepress.com/ testimonials.php to read real quotes from published authors.

Submit your manuscript here: http://www.dovepress.com/international-journal-of-nanomedicine-journal 